\title{
Letter to the editor: leptospirosis versus hantavirus infections in the Netherlands and in Belgium, 2000 to 2014
}

J Clement (jan.clement@uzleuven.be) ${ }^{1}$, M Van Esbroeck ${ }^{2}$, K Lagrou ${ }^{3}$, J Verschueren ${ }^{2}$, N P Sunil-Chandra ${ }^{4}$, M Van Ranst $^{1}$

1. National Reference Centre for Hantaviruses, Clinical and Epidemiological Virology, University Hospitals of Leuven, Leuven, Belgium

2. National Reference Laboratory for Leptospirosis, Department of Clinical Sciences, Institute of Tropical Medicine, Antwerp, Belgium

3. Department of Microbiology \& Immunology, Catholic University Leuven, and Clinical Department of Laboratory Medicine, University Hospitals of Leuven, Leuven, Belgium

4. Department of Medical Microbiology, Faculty of Medicine, University of Kelaniya, Sri-Lanka

Citation style for this article:

Clement J, Van Esbroeck M, Lagrou K, Verschueren J, Sunil-Chandra NP, Van Ranst M. Letter to the Editor: Leptospirosis versus hantavirus infections in the Netherlands and in Belgium, 2000 to 2014. Euro Surveill. 2014;19(38):pii=20912. Available online: http://www.eurosurveillance.org/ViewArticle. aspx?Articleld=20912

Article submitted on 10 September 2014 / published on 25 September 2014

To the editor: We fully agree with statements of Goeijenbier et al., who conducted a study on leptospirosis and hantavirus in the Netherlands [1], that hantavirus-induced haemorrhagic fever with renal syndrome (HFRS) often mimics leptospirosis [2]. Moreover, we confirm their findings with a parallel study in Belgium (Table), where, according to frequent practice, we screened for both pathogens from the start in sera of patients who presented with such similar symptoms. This resulted in only $55 / 1,580$ ( $3 \%$ ) patients serologically confirmed as having leptospirosis, whereas almost double, or 106 (7\%), appeared compatible with acute HFRS (hantavirus IgM positivity). This percentage is more than triple that found in the current Dutch study (about $2 \%$ ) [1]. In the authors view, this discrepancy is mainly due to a different screening practice, common in Belgium, and explaining the 1,525/1,580 (97\%) leptospirosis-negativity. Moreover, in the Dutch study, leptospirosis-positive cases have not been taken into account. Concomitant acute HFRS-leptospirosis co-infections have however previously been described, a finding now confirmed again in five Belgian cases (Table).

These dual acute infections are probably even more frequent in highly endemic tropical regions, as demonstrated very recently in Sri-Lanka (Sunil-Chandra, data not shown) by proving concomitant enzymelinked immunosorbent assay (ELISA) IgM-positivity for both pathogens in seven of 31 patients, hospitalised for leptospirosis. This illustrates that seroconfirmation (even by the gold standard microscopic agglutination test, MAT) of leptospirosis does not automatically exclude concomitant HFRS, a globally underestimated but evidence-based fact, having far-reaching epidemiological and therapeutical implications. Indeed, so-called 'therapeutical failures' with antibiotics in
TABLE

Serological results in a cohort of patients suspected for leptospirosis, or hantavirus infection, Belgium, 2000-2014 $(\mathrm{n}=1,580$ patients $)$

\begin{tabular}{|c|c|c|c|}
\hline $\begin{array}{l}\text { Number of } \\
\text { patients (\%) }\end{array}$ & Leptospirosis $^{a}$ & Hantavirus IgGb & Hantavirus Ig $\mathrm{M}^{\mathrm{b}}$ \\
\hline $1,390(88)$ & Negative & Negative & Negative \\
\hline $78(5)$ & Negative & Positive & Positive $^{c}$ \\
\hline $34(2)$ & Negative & Positive & Negative \\
\hline $23(1)$ & Negative & Negative & Positive $^{c}$ \\
\hline $50(3)$ & Positive & Negative & Negative \\
\hline $3(<1)$ & Positive & Negative & Positive $^{c}$ \\
\hline $2(<1)$ & Positive & Positive & Positive $^{c}$ \\
\hline
\end{tabular}

Grand Total: 1,580 .

a Leptospirosis serology was performed by microscopic agglutination test (MAT) with a threshold dilution of $1 / 50$ using eight to 10 strains belonging to between five and nine distinct serogroups. Leptospiral IgM presence was assessed by immunochromatographic assay (Core diagnostics, Birmingham, United Kingdom).

b For hantavirus serology, the Institute of Tropical Medicine, Antwerp, Belgium used IgG and IgM immunofluorescence assay (IFA) from 2000 to 2007 , followed by various commercial diagnostic enzyme-linked immunosorbent assays (ELISA), mostly and mainly based on both Korean prototype Hantaan virus (HTNV) and European Puumala virus (PUUV). The National Reference Centre for Hantaviruses, University of Leuven, Belgium, used, as a routine first screening step in hantavirus serology, HTNV and PUUV IgG and IgM ELISA (Progen, Heidelberg, Germany) (results in the current Table).

Results of eventually ensuing individual confirmation tests such as immunoblot, reverse transcription-polymerase chain reaction (RT-PCR), or focus reduction neutralisation tests (FRNT) were not considered for this Table. Consequently, IFA or ELISA results based only on positive IgM should be interpreted as very frequently, but not always, synonymous with acute hantavirusinduced haemorrhagic fever with renal syndrome.

leptospirosis, might partly be due to missed concomitant HFRS worldwide. 
The persistently lower numbers of registered HFRS cases in the Netherlands, compared to neighbouring countries (Belgium and Germany) [1], are not so much due to lower medical awareness, but to an absent or dampened effect of so-called 'mast years', cyclic two to three yearly abundant autumnal production of beechnuts, leading to local HFRS peaks [3]. The Netherlands have a low beech tree coverage of only 10 to $14 \%$, in contrast to Belgium with 24 to $33 \%$, and particularly to south Germany with 43 to $56 \%$, making south Germany the most HFRS-endemic area in west Europe [3]. It is probably not a coincidence that the very first (1988) cluster of Dutch HFRS cases was noted around Enschede and Oldenzaal in Twente [4]. This easternmost salient area of the Netherlands is the only part with a beech coverage of 24 to $33 \%$ [3]. We performed in 1988 a first local rodent capture action, confirming a high degree $(40 \%)$ of hantavirus infection of bank voles in that region of Twente [4], still nowadays the most endemic part of the country.

Hantavirus screening in leptospirosis-suspected patients is an attractive idea, but it is not new. Van der Groen et al. tested 682 Belgian leptospirosis-suspected sera, documenting in 26 (4\%) a IgG indirect fluorescent antibody (IFA) hantavirus-positivity, compared to only $21 / 950$ ( $2 \%$ ) in healthy blood donors [2]. Thus, already in 1983, a significantly higher hantavirus IgG prevalence in leptospirosis suspects, versus blood donors, was demonstrated (relative risk: 1.72; $95 \%$ confidence interval (Cl): 1.08-2.76) [2]. Expansion of this basic strategy during 11 subsequent years resulted in the most important leptospirosis versus HFRS study so far, confirming IgG IFA hantavirus-positivity in $2 \%$ $(44 / 2,055)$ of leptospirosis suspects, versus only $1 \%$ $(124 / 9,413)$ in blood donors $\left(X^{2}=10.5\right.$; p<0.001) in Belgium [5].

Evidence of a 'new' hantavirus, Seoul virus (SEOV), is not 'mounting in Europe', as the Dutch authors exemplify with two recent IFA-confirmed SEOV cases in England and Wales (References 22, 23 and 30 of the study under discussion). Use of exactly the same IFA technique, but expanded with a sensitive Chinese SEOV screening antigen R22, allowed, already two decades ago, the first discovery in Europe of 15 clinical SEOV-cases and one asymptomatic IgM-positive control in Northern Ireland [6]. Finally, this simple but almost never applied strategy for screening leptospirosis-suspected cohorts worldwide, enabled the first detection of clinically documented hantavirus cases in the New World (Brazil, 1993) [7], in India (2006) [8], and thus recently in Sri-Lanka.

\section{Acknowledgements}

We wish to thank the laboratory medicine IT people for retrieval of the data from the lab information system of the University Hospitals of Leuven, Belgium.
Conflict of interest

None declared.

Author contributions

J Clement conceived the idea and wrote the Letter, and did the bibliography. M Van Esbroeck performed the leptospirosis serology and part of the hantavirus serology, and helped writing the manuscript. K. Lagrou performed the hantavirus serology, initiated and supervised the hantavirus laboratory data bank screening at Leuven university, and constructed the Table. J Verschueren was responsible for the leptospirosis data bank screening. NP Sunil-Chandra was responsible for the mentioned leptospirosis and hantavirus data from Sri-Lanka. M Van Ranst supervised the hantavirus serology at Leuven university, and helped writing the manuscript.

\section{References}

1. Goeijenbier M, Hartskeerl R, Reimerink J, Verner-Carlsson J, Wagenaar J, Goris M, et al. The hanta hunting study: underdiagnosis of Puumala hantavirus infections in symptomatic non-travelling leptospirosis-suspected patients in the Netherlands, in 2010 and April to November 2011. Euro Surveill. 2014;19(32): pii=20878.

2. van der Groen G, Piot P, Desmyter J, Colaert J, Muylle L, Tkachenko EA, et al. Seroepidemiology of Hantaanrelated virus infections in Belgian populations. Lancet. 1983;2(8365-66):1493-4.

3. Clement J, Maes P, van Ypersele de Strihou C, van der Groen G, Barrios JM, Verstraeten WW, et al. Beechnuts and outbreaks of nephropathia epidemica (NE): of mast, mice and men. Nephrol Dial Transplant. 2010;25(6):1740-6. http://dx.doi.org/10.1093/ $\mathrm{ndt} / \mathrm{gfq} 122$

4. Jordans JG, Groen J, Clement J, Lefevre A, Haraldsdòttir V, Osterhaus AD. [Hantaan virus infection in Twente]. Ned Tijdschr Geneeskd. 1991;135(18):796-8. Dutch.

5. Clement J, McKenna P, Leirs H, van der Groen G. Leptospirosis (LSP) or rat-transmitted hantavirus (HV) nephropathy? Abstracts of the First Scientific Meeting of the Belgian Society of Nephrology, Liege, Belgium; 4 December 1993: Nephrol Dial Transplant. 1994; 9(6):723-32.

6. McKenna P, Clement J, Matthys P, Coyle PV, McCaughey C. Serological evidence of hantavirus disease in Northern Ireland. J Med Virol. 1994;43(1):33-8. http://dx.doi.org/10.1002/ jmv.1890430107

7. Hinrichsen S, Medeiros de Andrade A, Clement J, Leirs H, McKenna P, Matthys P, et al. Evidence of Hantavirus infection in Brazilian patients from Recife with suspected Leptospirosis. Lancet. 1993;341(8836):50. http://dx.doi. org/10.1016/0140-6736(93)92523-V

8. Clement J, Maes P, Muthusethupathi M, Nainan G, van Ranst $M$. First evidence of fatal hantavirus nephropathy in India, mimicking leptospirosis. Nephrol Dial Transpl. 2006;21(3):8267. http://dx.doi.org/10.1093/ndt/gfi334 